\title{
¿O emprego das TIC muda a metodoloxía na aula? Un estudo de caso
}

\author{
Tue use of ICT modifies the methodology in the classroom? A case study
}

\author{
Pilar Anta \\ Universidade da Coruña
}

\begin{abstract}
Resumen
A presente comunicación forma parte dun traballo de investigación máis amplo enmarcado na metodoloxía cualitativa. En concreto é un estudo de caso levado a cabo nun centro de ensino secundario de A Coruña.

O obxectivo principal era tratar de coñecer como influíu a implantación das TIC en distintos aspectos relacionados co centro e analizar as razóns das modificacións que se produciron.

O que pretendemos neste momento é amosar os achados en relación aos aspectos didácticos, é dicir, describir como a incorporación das TIC mudou as metodoloxías empregadas na aula e contrastar estas coas empregadas tradicionalmente polos docentes do centro.

Palabras clave: TIC, innovación educacional, papel del docente
\end{abstract}

\begin{abstract}
This communication is part of a broader research project framed in the cualitatvia methodology. In particular is a case study carried out at a university secondary in the province of A Coruña.

The main objective was to try to learn how the implementation of ICT in various aspects related to the Centre and analiar influenced the reasons of the changes that occurred.

Clain at this time is to show findings in relation to the educational aspects, i.e., describing how the incorporation of ICT changed methodologies employed in the classroom and contrast these with those used traditionally by teachers of the Centro.

Keywords: ITC, Educational innovations, Teacher role.
\end{abstract}

"A sociedade da información supón unha revolución que dota á intelixencia humana de novas e inxentes capacidades e constitúe un recurso que altera o modo en que traballamos e convivimos" (Bangemann, 1994, en Gargallo, Suárez e Díaz, 2003, p. 34).

Tradicionalmente o coñecemento transmitíase nas aulas, consideradas pouco menos que santuarios da cultura, pero na actualidade, inmersos na sociedade da información prodúcese un afastamento do avance cultural e a institución educativa.

A administración busca resolver dito problema dotando aos centros educativos coa infraestrutura dixital axeitada para romper esa distancia. Pero nós, igual que Area (2010, p. 79) preguntámonos “¿que sucede cando os ordenadores entran nas aulas?". A simple dotación de recursos ¿é quen de producir a renovación pedagóxica necesaria para achegar a escola á realidade social?

Xa que se nos fixamos na expectativa que supón a introdución das TIC na educación respecto do cambio pedagóxico, temos que ter en conta que este non só require de novas infraestruturas informáticas senón que precisa da adopción de novas metodoloxías e do desenvolvemento de novos contidos educativos así como de novos métodos de organización e colaboración tanto dentro do centro educativo como a nivel institucional.

E así, ao longo do curso 2013/2014, embarcámonos nun estudo de caso nun instituto de ensino secundario postobrigatorio, de titularidade pública que, desde o ano 2003, participa nun proxecto de renovación tecnolóxica a través da incorporación das novas tecnoloxías ás aulas grazas ao finanzamento dunha institución privada sen ánimo de lucro cuxo obxectivo é o de promover actividades nos ámbitos cultural e educativo e no campo da investigación e a ciencia.

Coa presente comunicación pretendemos dar a coñecer os achados ao longo desta investigación, cuxo obxectivo principal era tratar de coñecer como influíu a implantación das TIC en distintos aspectos relacionados co centro e analizar as razóns das modificacións que se producen. En concreto pretendemos centrarnos nos elementos do triángulo didáctico: docente, alumno, curriculum.

\section{Método}

Movémonos dentro da investigación cualitativa, que se caracteriza por producir datos descritivos que responden ás propias reaccións dos suxeitos estudados (Taylor e Bogdan, 1987, p.20), os actores principais do proxecto: dirección, profesorado e alumnado. E, en concreto, no marco dos estudos de caso, estudando o fenómeno contemporáneo da implantación das TIC dentro do contexto real dun IES (Yin, 1989 en González, 1994, p. 47). É dicir, a escola, é o caso en si.

\section{Participantes}

Como xa indicamos interésanos estudar a visión dos axentes implicados en todo o proceso confluíndo coa das propias investigadoras e sempre dentro do propio ambiente escolar. Considerando que a nosa pretensión é identificar a nivel de centro en que se mellorou coa incorporación das TIC nos distintos ámbitos do ensino, seguindo a selección baseada en criterios de Goetz e LeCompte (1988, en González, 1994, p. 86), escollemos como informantes a un representante de cada un deles. E así, representando á parte administrativa, seleccionamos ao director no momento da implantación do proxecto, en relación ao ámbito metodolóxico, a un profesor dos máis implicados no proxecto e que emprega a cotío o ordenador na súa práctica docente e, a nivel de aula a un grupo de catro alumnos de segundo de bacharelato con 
ampla experiencia no programa, xa que o centro onde cursaron a etapa anterior tamén se atopa inscrito no mesmo. Ademais buscouse á paridade en canto a xénero e unha grande capacidade de reflexión e análise.

En tódolos casos consideráronse as seguintes circunstancias:

- Coñecemento e vivencia do proceso de integración das TIC no centro.

- Dsiponibilidade horaria para participar na investigación.

- Interese en colaborar e implicación nos propósitos da investigación.

- Predisposición favorable no referente ás novas tecnoloxías.

\section{Instrumentos}

Considerando que o que nos interesa é a voz dos axentes implicados en todo o proceso, eliximos as entrevistas como instrumento fundamental na recollida de datos. Aínda que as complementamos con outra técnica que, segundo Simons (2011, p. 70), adoita empregarse nos estudos de caso e que é a análise de documentos.

Así realizamos sendas entrevistas individuais cos docentes implicados e unha entrevista en grupo co alumnado.

Ademais de recadar información interésanos implicar ao docente na análise das súas prácticas didácticas, polo que se deseña unha entrevista de tipo proactivo (Simons, 2011, p. 71). Mentres que co alumnado o que buscamos é promover a discusión de cara a un contraste de opinións sobre a realidade na aula, de aí o feito de decantarnos por unha entrevista en grupo (Woods, 1987 en González, 1994, p. 60).

Por outra parte e, empregando o termo intravistas fronte entrevistas, buscamos nos documentos os datos que xa están no sistema, intentando ser extremadamente coidadosas e obxectivas (Walker, 2002, p. 172). No ámbito didáctico, que nos interesa aquí, analizamos as producións do profesor implicado: programacións de aula, materiais didácticos, probas escritas e memorias de final de avaliación, prestando especial atención aos cursos e materiais da aula virtual do centro.

Unha vez recopilados os datos procedemos a abordar o proceso de codificación e categorización dos mesmos. Táboa 1.

Codificación. Categoría Didáctica

\begin{tabular}{ll}
\hline CÓDIGOS & \\
\hline Profesorado & \\
Alumnado & Obxectivos \\
Ensino & Contidos \\
& Metodoloxía \\
& Avaliación \\
\hline
\end{tabular}

A información obxecto desta comunicación corresponde coa categoría denominada didáctica na que, como indicamos anteriormente, exploramos como inflúe a integración das novas tecnoloxías nos elementos do triángulo didáctico, así como nas relacións entre eles.

\section{Resultados}

\section{Profesorado}

Ao longo do estudo parécenos que o profesorado ten claro que a incorporación das TIC ao ensino supón un cambio de roles. E así, o profesor fala do seu papel dentro da aula como que o profesor "ten que ser un pouco o orientador" $(E P 1,10)$, pero constatamos que se consolida o modelo de docente transmisor de coñecemento. El mesmo recoñece que non sempre representa ese rol porque "moitas veces se necesita transmitir unha serie de contidos" $(E P 1,10)$ e en alusión aos medios empregados refírese a "unha presentación de diapositivas máis ou menos ideal" (EP1, 10).

Por outra parte comprobamos que o uso máis estendido no Centro respecto aos recursos TIC é a plataforma MOODLE coa que o profesorado séntese cómodo, porque "permite dar o curso empregando o equipamento informático dunha forma máis parecida a como se facía antes" (ED1, 11).

Nunha revisión de cursos colgados na aula virtual do centro, atopamos que os recursos teñen maioritariamente dúas finalidades. Por unha parte, transmitir información a través de ligazóns a documentos ou páxinas web elaboradas polo propio docente na mesma plataforma, que resultan ser lineais, sen empregar multitexto ou hiperligazóns. E, por outra, actividades que consisten na recepción de exercicios en formato de texto ou cuestionarios obxectivos de resposta curta exacta autoavaliable.

No referente ás dificultades que atopan os docentes no seu labor diario destaca o medo á perda de tempo, debida ao mal funcionamento dos equipos e os tempos necesarios no arranque dos mesmos, e a perder o control do alumnado. Ademais perciben un perigo en que a práctica docente se converta nunha mitificación da aprendizaxe.

\footnotetext{
Alumnado

A incorporación das TIC permite outorgar ao alumno un papel moito máis activo no seu propio proceso de ensino-aprendizaxe: cambiar o rol, pasar de receptor de información a construtor do seu propio coñecemento. Pero se non hai un cambio de metodoloxía os recursos, por si mesmos, non producen dita transformación.

No noso estudio constatamos que os cambios veñen dados pola introdución do ordenador como instrumento de estudo. Sendo o uso do mesmo para buscar información, aclarar dúbidas procurando explicacións na rede, revisar exercicios xa resoltos que poida subir o profesorado á aula virtual e coller apuntamentos. Ademais parecen usar máis o ordenador para materias de letras que para as técnicas.

En canto á problemática desta forma de estudo o alumnado, cando fala en primeira persoa, destaca a facilidade para distraerse. Sen embargo, cando se refiren a compañeiros con dificultades na clase, recoñecen que o emprego do ordenador é un estímulo en si.
} 


\section{Ensino}

Tanto nas entrevistas como na revisión das programacións didácticas non atopamos cambios no apartado de obxectivos que poidamos achacar á incorporación das TIC. Tampouco se evidencia que se modifique dalgún xeito o cumprimento dos mesmos.

No referente ás mudanzas nos contidos traballados non atopamos maior evidencia que a necesaria actualización aos curriculums correspondentes a cada reforma educativa e que, en ocasións, están relacionados co emprego de recursos dixitais e software específico.

\section{Metodoloxía.}

Os cambios producidos na metodoloxía non son da magnitude que se podería esperar, nin se produce por igual en todos os docentes. O feito máis importante foi a introdución de MOODLE, pero no centro non se valora porque supuxese un cambio na didáctica senón porque, como comentamos anteriormente, permite seguir facendo o mesmo pero empregando os ordenadores. É dicir, perpetúase o modelo de profesor transmisor de coñecemento, cambiando o formato da información que pasa a distribuírse en dixital, levando nalgúns casos a eliminar o libro de texto. E o mesmo acontece coas actividades propostas.

A pesar disto a dinámica de aula vese alterada polo maior acceso á información que ten o alumnado, o que lles leva a poñer en xogo capacidades cognitivas máis complexas.

\section{Avaliación.}

Os nosos informantes, profesores e alumnos, coinciden en que a integración das TIC non modifica o modelo de avaliación. Pola súa parte os docentes recoñecen que non avalían os procesos senón o resultado como antes de empregar as novas tecnoloxías, mentres que o alumnado opina que o feito de que se avalíe o traballo do trimestre e non só o exame final depende do mestre en si e non do seu emprego das TIC.

As mudanzas que aluden uns e outros volven ser de formato.

\section{Discusión}

Aínda que apreciamos unha clara concienciación da necesidade de cambio de rol por parte do profesorado, constatamos que o que se modifican son os instrumentos ou a forma de impartir docencia, pero que se perpetúa o modelo de profesor transmisor de coñecementos, favorecida pola xeneralización do emprego de MOODLE na aula, que parece ser suficiente para xustificar o emprego das TIC no ensino.

A este respecto tanto Gewerc e Montero (2010, p. 314) coma Lankshear e Knobel (2011, p.65) coinciden na idea de que se perpetúan as metodoloxías tradicionais aínda que engadindo nalgún punto as novas tecnoloxías, pero sen modificar en absoluto a práctica docente. E, Area (2010, p. 94) apunta a que isto é así porque as TIC están sendo introducidas nas aulas como algo complementario á práctica tradicional.

Pola súa parte Coll, Mauri e Onurubia (2008, p. 10-13) realizaron un estudo de caso para analizar os usos reais das TIC en contextos educativos formais, concluíndo que “... teñen un efecto limitado na transformación e mellora das prácticas educativas..."

Por outra parte González (2008, p.6) nun traballo cunha mostra de profesorado da Universidade Autónoma de Tamaulipas en México, para medir a relación do acceso ás TIC e o tipo de práctica educativa, constataron que o $90 \%$ do mesmo segue empregando unha metodoloxía meramente transmisiva, utilizando os recursos unicamente como apoio á exposición nas súas clases.

De tódolos xeitos consideramos que cando estes complementos baséanse na proposta de actividades de busca guiada de información a través da rede, permiten ao alumnado poñer en xogo capacidades cognitivas máis complexas.

Por outra parte as mudanzas na transmisión de información e na proposta de actividades con respecto ao modelo tradicional é o cambio de formato, pasando do papel ao formato dixital en pdf. Non atopando evidencias significativas de introdución de actividades colaborativas nin interactivas.

O que si constatamos é que a chegada dos ordenadores non modificou a metodoloxía por igual entre todos os docentes do centro, aínda que a maior parte do profesorado introduciu o emprego de MOODLE na súa práctica docente, non implicando isto, necesariamente, un cambio de pedagoxía.

Xa en relación a isto Badía et al (en Cabero 2015, p. 25) apuntaban que "o reto non se atopa en desenvolver cursos tracionais en formato hipermedia senón máis en de ser capaces de adoptar novas perspectivas na concepción dos procesos de ensino-aprendizaxe e da construción de coñecemento":

Algo semellante apunta Cabero $(2015$, p. 21) cando fala de cambios na coreografía externa e non na interna, indicando que empregar as novas tecnoloxías para seguir facendo o mesmo na aula é un grande erro.

Tamén constatamos que os alumnos son conscientes de que non basta con dispoñer dos recursos para que mellore o seu concepto do centro educativo senón que o que valoran é como se empreguen eses recursos. E priorizan a importancia dun bo equipo de profesionais docentes ante a dotación de recursos informáticos.

Respecto das maiores dificultades que perciben os docentes para o emprego das TIC no ensino, atopamos os problemas na xestión de tempos, o control de alumnos e que o profesorado perda a noción do obxectivo a acadar, convertendo o emprego do ordenador nunha actividade libre sen rumbo, o laissez faire do que fala Area (2012, s.p.).

Por outra banda, o estudo realizado por Sepúlveda e Calderón (2007, p.3) amosa que moitos docentes consideran que a introdución das TIC na súa práctica educativa supón que non lles dea tempo a cumprir coa programación, mentres que o libro de texto lles proporciona un maior control do traballo do alumado limitando o proceso e sen posibilidades de saírse do establecido.

No noso estudo constatamos que os usos reais que o alumnado lle da ao ordenador como ferramenta didáctica son: buscar información, aclarar dúbidas, recoller 
apuntamentos en clase e buscar exercicios resoltos. Empregándoo máis nas materias de letras que nas técnicas.

Ademais apreciamos que o emprego do ordenador é percibido polo alumnado como un estímulo en si mesmo, debido a que achega máis o ensino á súa realidade de nativos dixitais (Prensky, 2001, p.1). Sen embargo, son conscientes de que o traballo coas TIC supón un esforzo persoal maior e que deben vencer a tendencia de distraerse con outras aplicacións distintas da educativa que estean empregando.

Neste sentido Benavides e Pedró (2007, p. 28) consideran que o emprego dos recursos dixitais para a aprendizaxe supón un enorme potencial para a mellora da actitude do alumnado xa que obriga a desenvolver capacidades cognitivas de orde superior ademais da creatividade e a interactividade, ao tempo que supón adquirir maiores responsabilidades respecto á súa aprendizaxe. Mentres que Sepúlveda e Calderón (2007, p.4) sinalan que o emprego do ordenador supón para o estudante un estímulo en si mesmo. E Cabero (2004, p.2), ao referirse ás funcións das TIC, cita a de constituírse coma unha fonte de motivación extrínseca para o estudantado.

Por outra parte, nós non apreciamos cambios significativos nos obxectivos didácticos nin nos contidos traballados, máis alá do emprego dalgún software específico relacionado coa materia impartida.

De cara a futuras investigacións propoñémonos afondar nos cambios producidos a nivel didáctico, ampliando e mellorando a elección dos informantes. De xeito que se podan establecer comparativas entre distintos niveis educativos. Para analizar, por exemplo, se as mudanzas producidas son, cualitativa e cuantitativamente, comparables na etapa de bacharelato e na de ciclos formativos. Incluso tendo en conta a idade dos alumnos, xa que se podería facer unha análise das diferenzas introducidas en ciclo medio e en ciclo superior.

\section{Referencias}

Area, M. (2010). El proceso de integración y uso pedagógico de las TIC en los centros educativos. Un estudio de casos. Revista de Educación, 352, 77-97. http://ecaths1.s3.amazonaws.com/cts/6847293 74.Formaci $\%$ C3\%B3n $\% 20$ del $\% 20$ profesorado $\% 20$ en \%20TIC.\%20El\%20gran\%20caballo\%20de\%20batall a..pdf

Area, M. (novembro, 2012) La docencia virtual: entre las viejas resistencias y los nuevos espejismos. Ponencia presentada en UBATIC+ I Encuentro Virtual sobre TIC y Enseñanza en el Nivel Superior. Buenos Aires. Argentina. Recuperado de http://ullmedia.udv.ull.es/watch_video.php?v=5AG 3NO5R4HD4

Benavides, F. e Pedró, F. (2007) Políticas educativas sobre nuevas tecnologías en los países iberoamericanos. Revista iberoamericana de educación, 45, 19-69. http://www.researchgate.net/publication/28204599_P olticas_educativas_sobre_nuevas_tecnologas_en_los_ pases_iberoamericanos

Cabero, J. (2004). Formación del profesorado en TIC. El gran caballo de batalla. Comunicación y Pedagogía. Tecnologías y Recursos didácticos, 195, 27-31. http://tecnologiaedu.us.es/cuestionario/bibliovir/jca11. pdf

Cabero, J. (2015). Reflexiones educativas sobre las tecnologías de la información y la comunicación. Tecnología, ciencia y educación, 1, 20-27.

Coll, C.,Mauri, M.T. e Onrubia, J. (2008). Análisis de los usos reales de las TIC en los contextos educativos formales: una aproximación socio-cultural. Revista Electrónica de Investigación Educativa, 10 (1), 1-18. http://redie.uabc. mx/index.php/redie/article/vie w/177/307

Gargallo, B. Suárez, J.M. e Díaz, M. I. (2003) La integración de las nuevas tecnologías en los centros: una aproximación multivariada. Centro de Investigación y Documentación Educativa https://books.google.es/books?id=UunxheT PhbkC\&printsec $=$ frontcover\&hl $=$ es\&source $=$ gbs_ge_ summary_r\&cad $=0 \# \mathrm{v}=$ onepage $\& \mathrm{q} \& \mathrm{f}=$ false

Gewerc, A. e Montero, L. (2010) De la innovación deseada a la innovación posible. Escuelas alteradas por las TIC. Profesorado. Revista de curriculum y formación del profesorado, 14 (1), 303-318. http://www.ugr.es/ recfpro/rev141 ART16.p df

González, M. (1994). Aprender a enseñar: mitos y realidades. A Coruña. Servizo de publicacións da UDC.

González, J. C. (2008). TIC y la transformación de la práctica educativa en el contexto de las sociedades del conocimiento. Revista de Universidad y Sociedad del Conocimiento RUSC, 5 (2) http://www.uoc.edu/rusc/5/2/dt/esp/gonzalez.html Lankshear, C. e Knobel, M. (2008). Nuevos alfabetismos. $\mathrm{Su}$ práctica cotidiana y el aprendizaje en el aula. Madrid. Morata.

Sepúlveda, M.P. e Calderon, I. (2007). Las TIC y los procesos de enseñanza-aprendizaje: la supremacía de las programaciones, los modelos de enseñanza y las calificaciones ante las demandas de la sociedad del conocimiento. Revista Iberoamericana de Educación, 44

(5) http://www.rieoei.org/deloslectores/2195Ruiz.pdf Simons, H. (2011). El estudio de caso: Teoría y práctica. Madrid. Morata.

Taylor, S.J. e Bogdan, R. (1987). Introducción a los métodos cualitativos de investigación. Barcelona. Paidós.

Walker, R. (2002) Métodos de investigación para el profesorado. Técnicas de evaluación. (3a ed.). Madrid. Morata. 